\title{
Targeted Lung Expression of Interleukin-11 Enhances Murine Tolerance of $100 \%$ Oxygen and Diminishes Hyperoxia-induced DNA Fragmentation
}

\author{
Aaron B. Waxman, ${ }^{\star}$ Oskar Einarsson, ${ }^{\star}$ Tamas Seres, ${ }^{\ddagger}$ Roy G. Knickelbein, ${ }^{\ddagger}$ Joseph B. Warshaw, ${ }^{\ddagger}$ Robert Johnston, ${ }^{\ddagger}$ \\ Robert J. Homer, ${ }^{\S}$ and Jack A. Elias* \\ $*$ Section of Pulmonary and Critical Care Medicine, Department of Internal Medicine; ${ }^{\star}$ Department of Pediatrics, Department of Internal \\ Medicine; and ${ }^{\S}$ Department of Pathology, Yale University School of Medicine, New Haven, Connecticut 06520
}

\begin{abstract}
Acute lung injury is a frequent and treatment-limiting consequence of therapy with hyperoxic gas mixtures. To determine if IL-11 is protective in oxygen toxicity, we compared the effects of $100 \% \mathrm{O}_{2}$ on transgenic mice that overexpress IL-11 in the lung and transgene $(-)$ controls. IL-11 markedly enhanced survival in $100 \% \mathrm{O}_{2}$ with $100 \%$ of transgene $(-)$ animals dying within $72-96 \mathrm{~h}$ and $>90 \%$ of transgene $(+)$ animals surviving for more than $10 \mathrm{~d}$. This protection was associated with markedly diminished alveolar-capillary protein leak, endothelial and epithelial membrane injury, lipid peroxidation, and pulmonary neutrophil recruitment. Significant differences in copper zinc superoxide dismutase and catalase activities were not noted and the levels of total, reduced and oxidized glutathione were similar in transgene $(+)$ and ( -$)$ animals. Glutathione reductase, glutathione peroxidase, and manganese superoxide dismutase activities were slightly higher in transgene $(+)$ as versus $(-)$ mice after $100 \% \mathrm{O}_{2}$ exposure, and IL-11 diminished hyperoxiainduced expression of IL-1 and TNF. Hyperoxia also caused cell death with DNA fragmentation in the lungs of transgene (-) animals and IL-11 markedly diminished this cell death response. These studies demonstrate that IL-11 markedly diminishes hyperoxic lung injury. They also demonstrate this protection is associated with small changes in lung antioxidants, diminished hyperoxia-induced IL-1 and TNF production, and markedly suppressed hyperoxia-induced DNA fragmentation. (J. Clin. Invest. 1998. 101:1970-1982.) Key words: oxygen toxicity - lung injury • pulmonary edema $\cdot$ apoptosis $\cdot$ IL-11 and necrosis
\end{abstract}

\section{Introduction}

Supplemental oxygen is commonly given to patients with acute and chronic cardiovascular and pulmonary diseases in an at-

Address correspondence to Jack A. Elias, M.D., Section of Pulmonary and Critical Care Medicine, Yale University School of Medicine, Department of Internal Medicine, 333 Cedar Street - 105 LCI, New Haven, CT 06520-8057. Phone: 203-785-4163; FAX: 203-785-3826; E-mail: jack.elias@yale.edu

Received for publication 29 July 1997 and accepted in revised form 1 March 1998.

J. Clin. Invest.

(C) The American Society for Clinical Investigation, Inc. 0021-9738/98/05/1970/13 \$2.00

Volume 101, Number 9, May 1998, 1970-1982

http://www.jci.org tempt to increase alveolar and arterial oxygen tension, augment tissue oxygen delivery and minimize the adverse effects of hypoxia. Oxygen can, however, also have detrimental effects since it is a major stimulus for the generation of reactive oxygen species. This is an important clinical problem at toxic oxygen concentrations (generally believed to be a fractional inspired $\mathrm{O}_{2}$ concentration above $50 \%$ ). It is a pressing issue when patients require $100 \%$ oxygen which rapidly causes acute lung injury with endothelial cell destruction, alveolar epithelial injury and increased pulmonary capillary permeability (1-3). When severe, respiratory failure from the acute respiratory distress syndrome and death $(4,5)$ can be seen.

Interleukin-11 (IL-11) is a $20-\mathrm{kD}$ cationic member of the IL-6-type cytokine family. It was originally described as the molecule other than IL-6 in transformed stromal cell supernatants that stimulated plasmacytoma cell proliferation (6). It is now known to be pleiotropic with a wide range of effects on hematopoiesis, and the ability to inhibit lipoprotein lipase and stimulate the production of immunoglobulins, the tissue inhibitor of metalloproteinase- 1 and the acute phase response (for review see reference 7). Recently, IL-11 has been shown to have protective effects in the gastrointestinal tract. This was initially described after combined chemotherapy and radiation therapy $(8,9)$ and has since been noted in acetic acid-induced colitis (9), hapten-induced colitis (10), the inflammatory bowel disease in HLAB-27 transgenic mice (9), and ischemic colitis (11). Studies from our laboratory (12) have shown that IL-11 can also have protective effects at extra-abdominal sites since it enhances the survival of mice exposed to thoracic radiation. The effects of IL-11 in the setting of other pulmonary injuries, in particular oxygen toxicity, have not been investigated.

We hypothesized that IL-11 could ameliorate hyperoxiainduced pulmonary injury. To test this hypothesis, we characterized the $\mathrm{O}_{2}$ tolerance of wild-type and transgenic mice, prepared in our laboratory, in which IL-11 was overexpressed in a lung-specific fashion. These studies demonstrate that IL-11 overexpressing mice, in comparison to their transgene $(-)$ littermates, exhibit a remarkable tolerance to the toxic effects of hyperoxia. The transgene $(+)$ animals manifest impressively enhanced survival and decreased lung lipid peroxidation, neutrophil recruitment, alveolar-capillary protein leak and pulmonary edema. They also demonstrate that this protection is associated with insignificant or small alterations in the lung levels of important antioxidants and an impressive decrease in hyperoxia-induced cell death and DNA fragmentation.

\section{Methods}

\section{Generation of transgenic mice}

A variety of transgenic mice were used in these studies. These mice were generated using $\mathrm{CBA} \times \mathrm{C} 57 \mathrm{BL} / 6$ animals and bred onto a C57 BL/6 background. 
Clara cell 10-kD protein promoter $(C C 10)^{1}-I L-11$ mice. These transgenic mice constitutively overexpress IL-11 in a lung-specific fashion. The methods that were used in our laboratory to generate these mice, the organ specificity of transgene targeting, and the pathologic alterations induced by IL-11 have been described previously (13). Transgene (-) littermate mice were used as controls in these experiments.

CC10-IL-16 mice. These transgenic mice use CC10 to drive the expression of cDNA encoding IL-16 in a lung specific fashion. They were prepared using techniques previously described by our laboratory (13). The IL-16 cDNA that was used was obtained from Dr. David Center and Dr. William Cruickshank (Boston University, Boston, MA) and contained the coding sequence of IL-16 as described previously (14). Transgene ( - ) littermate mice were used as controls in these experiments.

CC10-reverse tetracycline transactivator (rtTA)-hIL-11 mice. These transgenic mice overexpress IL-11 in the lung in an inducible fashion. The approaches used in our laboratory to generate these mice have been described (15). To achieve inducibility we generated dual transgene (+) animals. The first construct uses the $\mathrm{CC} 10$ promoter to target the rtTA of Gossen et al. (16) to the lung. The second construct contains multimers of the tetracycline operator, minimal cytomegalovirus promoter and IL- 11 cDNA. These animals have very low to undetectable levels of IL-11 in their lungs at baseline and $\mathrm{ng} / \mathrm{ml}$ quantities after transgene induction by adding doxycycline $(1 \mu \mathrm{g} / \mathrm{ml})$ to the animal's drinking water (dox water). Transgene $(-)$ mice on normal and dox water and dual transgene $(+)$ mice on normal water were used as controls for these experiments.

\section{Oxygen exposure}

Mice were exposed to $100 \%$ oxygen in a $50 \times 30 \times 30 \mathrm{~cm}$ airtight chamber. The fractional inspired $\mathrm{O}_{2}$ concentration in the chamber was monitored with an in-line oxygen analyzer (Vascular Technology, Inc., Chelmsford, MA) and maintained with a constant flow of gas $(\sim 3$ liters $/ \mathrm{min})$. The mice were fed food and water ad lib and kept on a $12 \mathrm{~h}$ dark-light cycle at sea level and at room temperature. The animals were monitored at intervals for signs of respiratory difficulty and killed if there were signs of respiratory distress.

\section{Bronchoalveolar lavage}

After anesthesia, a median sternotomy was performed, the trachea was dissected free from the underlying soft tissues and a 0.6- $\mathrm{mm}$ tube was inserted through a small incision in the trachea. Bronchoalveolar lavage (BAL) was performed by perfusing the lungs in situ with $0.6 \mathrm{ml}$ PBS and then gently aspirating the fluid back. This was repeated three times. The samples were then pooled, centrifuged and cell numbers and differentials were assessed. The cell-free BAL fluid was stored at $-70^{\circ} \mathrm{C}$ until used.

\section{Light microscopy}

Mice were anesthetized, a median sternotomy was performed, and the trachea was dissected free and cannulated as described above. The lungs were then perfused in situ, inflated to $20 \mathrm{~cm}$ water pressure with $10 \%$ formalin in PBS ( $\mathrm{pH} 7.40$ ), removed and post-fixed in $10 \%$ formalin in PBS for $24 \mathrm{~h}$. Tissue from all lung lobes were dehydrated, infiltrated and embedded in paraffin, and stained with hematoxylin and eosin.

\section{Electron microscopy}

Lungs were isolated and the trachea cannulated as described above. The lungs were then perfused in situ to $20 \mathrm{~cm}$ water pressure with $3.5 \%$ gluteraldehyde, post-fixed for $24 \mathrm{~h}$ in $3.5 \%$ gluteraldehyde and

1. Abbreviations used in this paper: $\mathrm{BAL}$, bronchoalveolar lavage; CC10, clara cell 10-kD protein promoter; DTNB, 5, 5'-dithiobis[2-nitrobenzoic acid]; GSH, glutathione; GSSG, oxidized glutathione; rtTA, reverse tetracycline transactivator; TUNEL, TdT-mediated dUTP-biotin nick end labeling. representative areas embedded in epon. Ultrathin sections of embedded tissue were prepared, stained with $2 \%$ uranyl acetate and $\mathrm{OsO}_{4}$ and examined using a Phillips EM300 electron microscope (Phillips, Amsterdam, The Netherlands).

\section{$B A L$ protein and lung lipid peroxidation}

$B A L$ protein. BAL was performed as described above and BAL protein was assayed as an index of lung injury and capillary leak. Protein quantification was accomplished using the method of Lowery.

Lung lipid peroxidation. Lungs were isolated and perfused with ice cold $0.9 \% \mathrm{NaCl}$, and homogenates were prepared in ice-cold $20 \mathrm{mM}$ Tris- $\mathrm{HCl}(\mathrm{pH} 7.40)$. The homogenates were then centrifuged at $3,000 \mathrm{~g}$ at $4^{\circ} \mathrm{C}$ for $10 \mathrm{~min}$ and $200 \mu \mathrm{l}$ of the supernatant was removed for the assay. Lipid peroxidation was assessed by quantitating the interaction of a chromogenic reagent with malonaldehyde and 4-hydroxyalkenals (17) using the LPO-586 kit (Calbiochem Corp., San Diego, CA). Data was expressed as $\mathrm{mM}$ of products of lipid peroxidation in $200 \mu \mathrm{l}$ of a $20 \% \mathrm{wt} / \mathrm{vol}$ solution of lung homogenate.

\section{Assessments of antioxidants}

Superoxide dismutase (SOD). The SODs were assayed using the gel electrophoresis method of Beauchamp and Fridovich (18). This assay is based on the ability of SOD in a polyacrylamide gel to inhibit the reduction of nitro-blue tetrazolium by superoxide anion generated using photochemically reduced riboflavin. Lung homogenates were prepared in $3 \mathrm{ml}$ potassium phosphate buffer and $1.0 \mathrm{mM}$ EDTA, sonicated for $3 \mathrm{~min}$ and centrifuged at 15,000 $\mathrm{g}$. Equal amounts of supernatant protein were run in a $10 \%$ polyacrylamide gel until the bromophenol blue marker dye came off the end of the apparatus. The gel was then placed in a solution of $2.45 \times 10^{-3} \mathrm{M}$ nitroblue tetrazolium for $20 \mathrm{~min}$, immersed in a TEMED, riboflavin, and potassium phosphate solution for $15 \mathrm{~min}$, and illuminated with a $15 \mathrm{~W}$ fluorescent light for $15 \mathrm{~min}$. During illumination the gels become uniformly blue except for areas containing SOD. Purified Escherichia coli Mn-SOD and bovine erythrocyte $\mathrm{CuZn}$-SOD were used to generate standard curves from which lung extract Mn-SOD and CuZn-SOD activities were measured.

Total glutathione. The concentrations of total glutathione and its components, reduced glutathione (GSH) and glutathione disulfide (oxidized glutathione; GSSG) were obtained using the enzymatic recycling assay as described by Griffith (19). Frozen samples of lung were homogenized in 10\% 5-sulfosalicylic acid and centrifuged at $800 \mathrm{~g}$ for $30 \mathrm{~s}$ to remove cell debris. The supernatant was added to a reaction mixture containing glutathione reductase, NADPH, and $5,5^{\prime}-$ dithiobis-[2-nitrobenzoic acid] (DTNB). The reduction of DTNB was measured at $412 \mathrm{~nm}$, and results compared with a GSH standard curve. GSH is inactivated by derivitization with 2-vinylpyridine. By performing this derivitization before measuring DTNB reduction, GSSG levels could be selectively determined and GSH levels calculated.

Catalase, glutathione reductase, and glutathione peroxidase. Lung tissue was diluted fourfold with sucrose buffer, gently homogenized with a polytron at low speed, then microfuged for $30 \mathrm{~s}$ to remove all debris. The resulting homogenate was aliquoted into $100 \mu \mathrm{l}$ samples for each enzyme assay and frozen on dry ice or used immediately. All measurements were standardized per milligram of protein. Control curves were generated using purified purchased enzymes (Sigma Chemical Co., St. Louis, MO).

Catalase activity was determined by following the decomposition of $\mathrm{H}_{2} \mathrm{O}_{2}$ over time. This was performed by adding $\mathrm{H}_{2} \mathrm{O}_{2}$ to lung extracts and making repeated measurements of absorbance at $240 \mathrm{~nm}$ as described by Aebi (20).

Glutathione peroxidase oxidizes GSH to GSSG in the presence of $\mathrm{H}_{2} \mathrm{O}_{2}$. As described by Flohe and Gunzler (21) the glutathione peroxidase activity was determined by adding lung homogenate to a reaction mixture containing excess GSH $(1 \mathrm{mM})$ and $1 \mathrm{mM}$ sodium azide to inhibit endogenous catalase. The reaction was started by adding $1 \mathrm{mM}$ $\mathrm{H}_{2} \mathrm{O}_{2}$, and after 1 min stopped with $10 \%$ 5-sulfosalicylic acid. The re- 
maining GSH was derivatized with 2-vinylpyridine and GSSG determined by measuring DTNB reduction as described above.

Glutathione reductase converts GSSG to GSH in an NADPHdependent reaction. Using the method of Bellomo et al. (22), glutathione reductase was determined by adding lung homogenate to a pH 7.0 buffer containing $50 \mu \mathrm{M}$ GSSG, then measuring the oxidation of NADPH spectrophotometrically at $340 \mathrm{~nm}$.

\section{Isolation and detection of RNA}

mRNA levels were quantitated by Northern blot analysis. Briefly, mice were anesthetized as above, the right heart perfused with ice cold PBS ( $\mathrm{pH} 7.40$ ), and the lungs removed and homogenized in TRIzol Reagent (Life Technologies, Gaithersburg, MD). Total RNA was then obtained by processing the tissues according to the manufacturer's specifications. When mRNA was employed it was isolated using the Oligotex mRNA kit (QIAGEN, Inc., Chatsworth, CA). Equal amounts of total or poly A+ enriched RNA were electrophoresed in $1 \%$ agarose, $17 \%$ formaldehyde gels in a $20 \mathrm{mM} 3$-[ $N$-Morpholino]propanesulfonic acid (Mops) running buffer and then transferred to a nitrocellulose membrane and baked at $60^{\circ} \mathrm{C}$ for $2 \mathrm{~h}$. The levels of mRNA for specific proteins were assessed by hybridization with ${ }^{32} \mathrm{P}$ labeled mouse cDNA probes encoding Mn-SOD (a gift from Dr. YeShih Ho, Wayne State University, Detroit, MI), IL-1 $\beta$ and TNF- $\alpha$ (American Type Culture Collection, Rockville, MD) as described previously (12). Radiolabeled mRNA was visualized by autoradiography and densitometry.

\section{Quantification of bronchoalveolar lavage proteins}

The IL-1 $\beta$ and TNF- $\alpha$ in BAL fluid were quantitated with ELISA kits (Endogen, Cambridge, MA) using the instructions provided by the manufacturer.

\section{Measurement of DNA fragmentation}

DNA fragmentation was quantified using the TdT-mediated dUTPbiotin nick end labeling (TUNEL) method and by demonstrating DNA disruption with gel electrophoresis.

TUNEL method. This technique employs fragment end labeling of exposed $3^{\prime}-\mathrm{OH}$ ends of DNA in paraffin embedded tissue. Cells were labeled with the TdT Blue label (Trevigen, Gaithersburg, MD) using the instructions provided by the manufacturer. This stain allowed all nuclei to be easily visualized. After staining, five fields of alveoli were randomly chosen and 500 nuclei were counted. The labeled cells was expressed as a percentage of total nuclei.

Gel electrophoresis. DNA was isolated from the lungs of transgene $(+)$ and transgene $(-)$ mice as previously described (13). The $3^{\prime}$ ends of purified DNA were labeled with $\left[{ }^{32} \mathrm{P}\right] \mathrm{dCTP}$ using the klenow fragment of DNA polymerase I. Equal quantities of DNA were loaded and run on $2 \%$ agarose gels. Autoradiography was used to demonstrate DNA damage. The size of the DNA fragments were compared with a DNA sizing ladder that was run in a nearby lane (100 bp DNA ladder; GIBCO BRL, Gaithersburg, MD).

\section{Statistical analysis}

Data are expressed as means \pm SEM. Normally distributed data were assessed for significance by Student's $t$ test or ANOVA as appropriate. Data that were not normally distributed were assessed for significance by the Fisher's exact rank sum test. Differences in survival between transgene $(+)$ and transgene $(-)$ animals were assessed using $\chi^{2}$ analysis.

\section{Results}

Effect of IL-11 on survival. To determine if IL-11 has the ability to ameliorate $\mathrm{O}_{2}$ toxicity we compared the survival of CC10-IL-11 mice and their wild-type littermate controls in $100 \% \mathrm{O}_{2}$. In keeping with the observations of others $(2,23$, 24), all of the transgene (-) littermate control mice died within $72 \mathrm{~h}$ of the initiation of $100 \% \mathrm{O}_{2}$. In contrast, the trans-

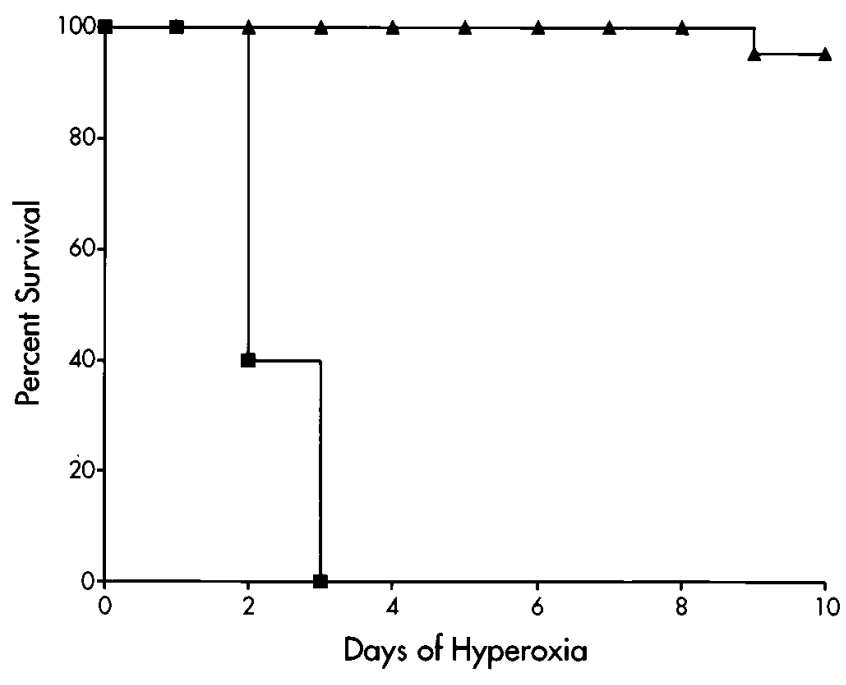

Figure 1. Survival of CC10-IL-11 mice exposed to $100 \% \mathrm{O}_{2}$. Comparisons are made of transgene (+; triangles) and (-; squares) littermate animals. Each value illustrates the percent survival of 20 mice.

gene $(+)$ mice were remarkably tolerant to $100 \% \mathrm{O}_{2}$ (Fig. 1). All the transgene $(+)$ animals survived for at least $8 \mathrm{~d}$ in $100 \%$ $\mathrm{O}_{2}$ and $>90 \%$ of these animals survived for $10 \mathrm{~d}$ or more in this hyperoxic environment $(P<0.001)$ (Fig. 1). During their time in $100 \% \mathrm{O}_{2}$ the transgene $(+)$ animals exhibited normal behavior and normal levels of activity.

Specificity of the effects of IL-11. Studies were undertaken to determine if the enhanced survival of CC10-IL-11 animals was the result of the IL-11 transgene or some other aspect of the transgenic system. This was done by determining if similar levels of protection were seen when the identical transgenic system was used to express an IL-16 transgene. The CC10IL-16 transgene $(+)$ mice were as sensitive to $100 \% \mathrm{O}_{2}$ as the transgene $(-)$ mice with $100 \%$ surviving $<90 \mathrm{~h}$ in $100 \% \mathrm{O}_{2}$ (data not shown). Thus, the enhanced survival of the $\mathrm{CC10}$ IL-11 mice is the result of the IL-11 transgene and is not the result of the CC10 transgene, the insertion of plasmid DNA into the mouse genome or the expression of human proteins in the mouse lung.

Effect of IL-11 on pulmonary histology and ultrastructure. To address the mechanism(s) of IL-11-induced protection in the setting of $100 \% \mathrm{O}_{2}$, we compared the gross pathologic features, microscopic features, and ultrastructural features of the lungs of transgene $(+)$ and $(-)$ CC10-IL-11 mice exposed to $100 \% \mathrm{O}_{2}$. Grossly, hyperoxia caused the lungs of the transgene (-) animals to become hemorrhagic and boggy. These alterations were present after as little as $48 \mathrm{~h}$ of $100 \% \mathrm{O}_{2}$ exposure. In contrast, transgene $(+)$ animals had normal appearing pleural surfaces and their lungs were not boggy and did not contain hemorrhage (data not shown). Microscopically, after $72 \mathrm{~h}$ in $100 \% \mathrm{O}_{2}$, the lungs of transgene $(-)$ animals manifest gross pulmonary edema. Hyaline membranes were also appreciated. Pulmonary edema and hyaline membranes were not appreciated in the CC10-IL-11 animals at similar time points (Fig. 2 and data not shown).

Even with severe hyperoxia-induced lung injury, alterations in individual cells can be difficult to appreciate by light microscopy $(1,25)$. However, blebbing and degeneration of alveolar 

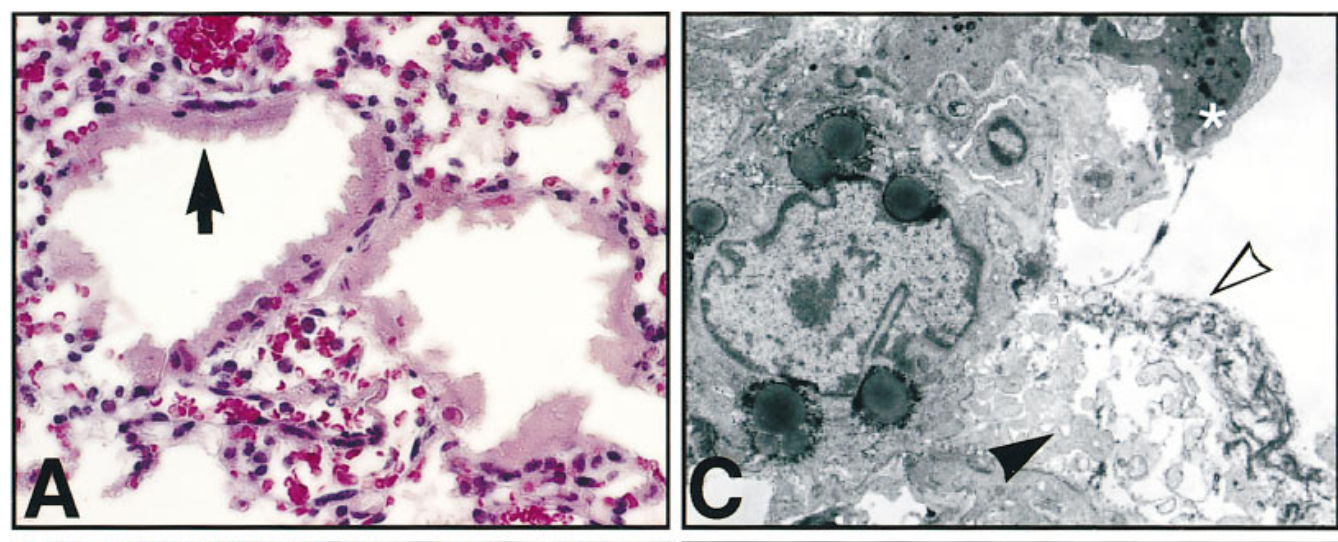

Figure 2. Histologic and ultrastructural comparisons of transgene (-) and transgene $(+)$ animals after exposure to $100 \% \mathrm{O}_{2}$ for $72 \mathrm{~h}$. The light microscopic studies are in $A$ and $B$ and the electron microscopic studies are in $C$ and $D$. The hyaline membranes can be readily seen by light microscopy in the alveoli of transgene (-) animals (solid
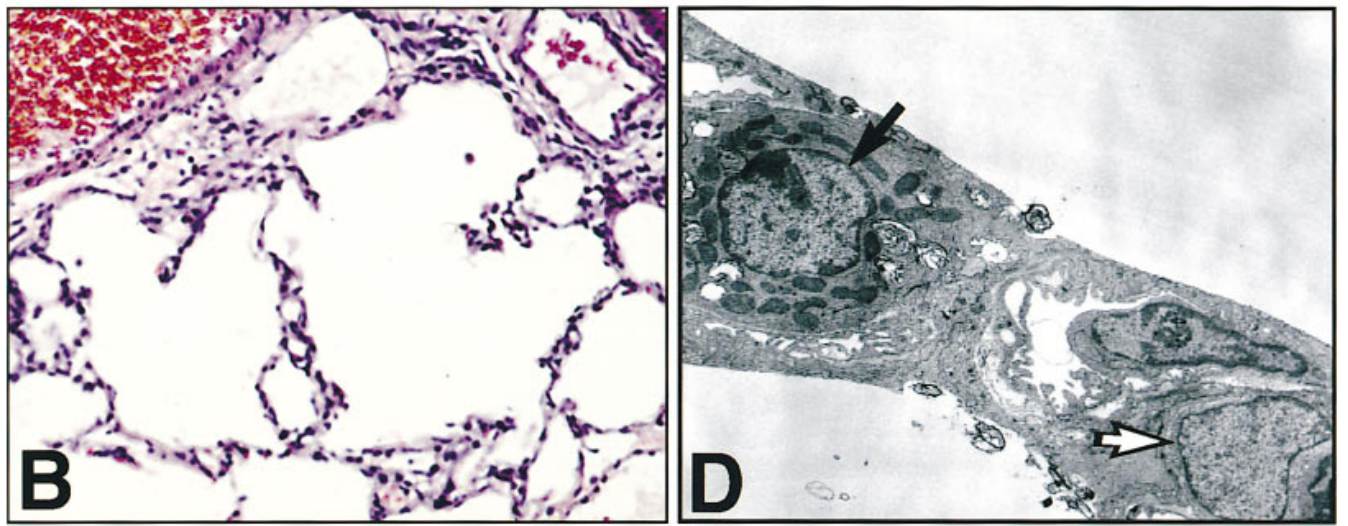
arrow, $A$ ), but not transgene $(+)$ animals $(B)$. $C$ illustrates the bleb formation and membrane ruffling (solid arrowhead), hyaline membrane material (hollow arrowhead), and granulocytes (asterisk) in the lungs of transgene (-) animals. In contrast, alveolar type II (solid arrow) and type I (hollow arrow) cells from transgene $(+)$ animals have normal appearing membranes $(D)$.

epithelial cell and endothelial cell membranes can be readily appreciated by electron microscopy (2). Similar findings were noted in our studies. Cell damage manifest as membrane ruffling and bleb formation was readily appreciated in the lungs of the transgene ( - ) animals after as little as $48 \mathrm{~h}$ of hyperoxic exposure (Fig. 2). In contrast, the membranes of the transgene $(+)$ animals had a normal ultrastructural appearance, even after $8-10 \mathrm{~d}$ of $100 \% \mathrm{O}_{2}$ (Fig. 2 and data not shown).

Effect of IL-11 on alveolar-capillary protein leak. To further characterize the protective effects of IL-11, we compared the levels of protein in the BAL fluids from the transgene $(+)$ and transgene ( - ) animals at intervals before and after the initiation of the hyperoxic exposure. At baseline the levels of BAL protein were similar in the transgene $(+)$ and $(-)$ mice (Fig. 3). In contrast, impressive differences were noted after $\mathrm{O}_{2}$ administration. These differences were readily appreciated after $48 \mathrm{~h}$ of $\mathrm{O}_{2}$ exposure and even more prominent after $72 \mathrm{~h}$ of hyperoxia. At the latter time point, transgene $(-)$ and trans-

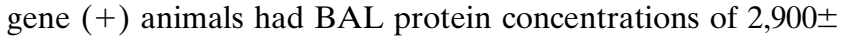
$446 \mu \mathrm{g} / \mathrm{ml}$ and $250 \pm 71 \mu \mathrm{g} / \mathrm{ml}$, respectively $(P<0.005 ;$ Fig. 3$)$.

Effect of IL-11 on BAL cellularity and differential. Oxygen toxicity is associated with an influx of neutrophils into the lung $(26,27)$. To assess the impact of IL-11 on hyperoxia-induced cellular alterations, we compared the BAL cell counts and differentials of CC10-IL-11 transgene $(+)$ and transgene $(-)$ animals before and after exposure to $100 \% \mathrm{O}_{2}$. At baseline, similar levels of BAL cellularity were seen in the transgene $(+)$ and (-) animals (Fig. $4 A$ ). In addition, comparable hyperoxia-induced increases in BAL cellularity were seen in the transgene $(+)$ and $(-)$ animals. In both groups BAL cell counts increased by $\sim 300 \%$ over the $72 \mathrm{~h}$ exposure (Fig. $4 A$ ).
The cellular differentials were also similar at baseline in the transgene (-) and (+) mice (Fig. 4, B-D). Impressive differences were noted, however, after $\mathrm{O}_{2}$ exposure. $100 \% \mathrm{O}_{2}$ caused a significant increase in BAL neutrophils in the transgene $(-)$ animals, but not in the transgene $(+)$ animals (Fig.

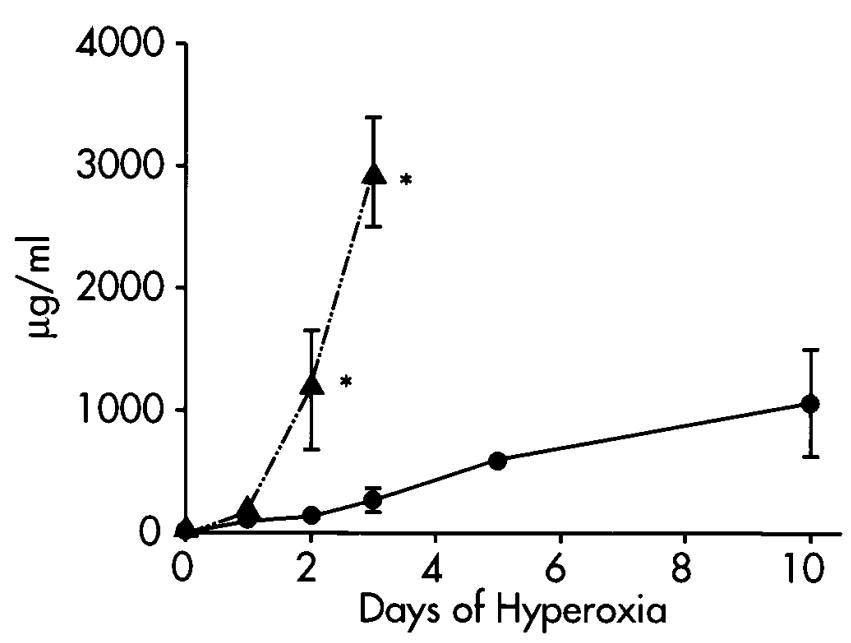

Figure 3. BAL protein content of transgene $(-)$ and $(+)$ mice. BAL was performed on CC10-IL-11 transgene (-; triangles) and transgene $(+;$ circles $)$ mice at the noted time points before and after exposure to $100 \% \mathrm{O}_{2}$. The levels of BAL protein were assessed as described in Methods. The values represent the mean \pm SEM of determinations performed on six animals at each time point. $\left({ }^{*} P<0.05\right.$ versus transgene $[+]$ animals at the same time point.) 
A
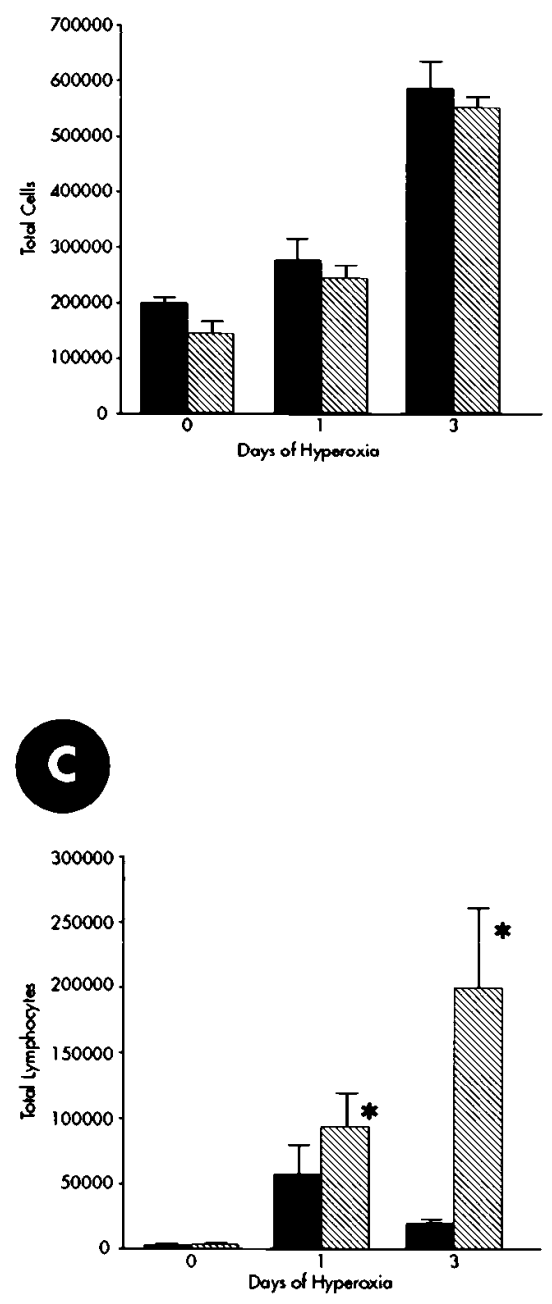

\section{B}

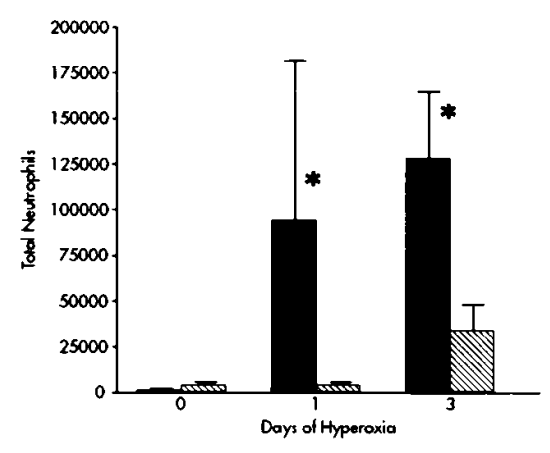

D

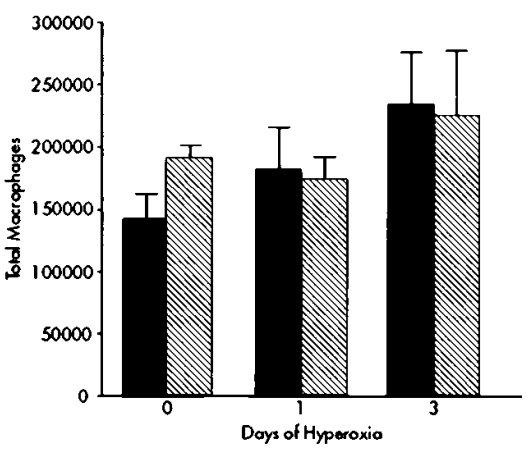

Figure 4. Cells in BAL fluid from transgene $(-)$ and transgene $(+)$ animals. Transgene $(+)$ CC10-IL-11 mice (hatched bars) and control littermate mice (solid bars) were evaluated at intervals before and after exposure to $100 \%$ $\mathrm{O}_{2}$. The total number of cells $(A)$, total number of neutrophils $(B)$, total number of lymphocytes $(C)$, and total number of macrophages $(D)$ in the BAL fluids were quantitated. The noted values represent the mean \pm SEM of at least six animals at each time point. ( $B$ and $C$, $* P<0.05$ compared with transgene $[-]$ animals at corresponding time points.)
$4 B)$. This difference could be appreciated after as little as $24 \mathrm{~h}$ of exposure to $100 \% \mathrm{O}_{2}$ (Fig. $4 \mathrm{~B}$ ). After $72 \mathrm{~h}$ of hyperoxia, similarly impressive differences were noted with transgene $(-)$ and $(+)$ animals having $128.4 \times 10^{3} \pm 36 \times 10^{3}$ and $34 \times$ $10^{3} \pm 13.4 \times 10^{3}$ neutrophils recovered in BAL fluid, respectively $(P<0.005)$. Exposure to $100 \% \mathrm{O}_{2}$ also caused small, but significant, increases in the number of lymphocytes recovered in BAL fluid from both transgene $(+)$ and $(-)$ mice. The levels in the BAL fluid of the transgene $(+)$ animals were, however, significantly greater than those in the transgene $(-)$ animals (Fig. $4 C)(P<0.05)$. After $72 \mathrm{~h}$ in $100 \% \mathrm{O}_{2}$, the number of lymphocytes in the BAL fluid of the transgene $(-)$ animals returned toward baseline. In contrast, a further increase in BAL lymphocyte numbers was appreciated in the transgene $(+)$ animals. Interestingly, comparable alterations in BAL macrophage numbers were not noted since similar numbers of macrophages were recovered by BAL in transgene $(+)$ and $(-)$ animals after $100 \%$ oxygen exposure (Fig. 4 D). When viewed in combination, these studies demonstrate that the targeted expression of IL-11 in the lung alters the types of leuko- cytes that accumulate in the air spaces of the lung after exposure to $100 \% \mathrm{O}_{2}$. Specifically, IL-11 minimizes granulocyte accumulation while simultaneously augmenting lymphocyte accumulation.

Effect of IL-11 on lung lipid peroxidation. The toxic effects of $\mathrm{O}_{2}$ are mediated, in part, by lipid peroxidation. To gain insight into the mechanism(s) of IL-11-induced protection we compared the levels of lipid peroxidation in lung homogenates from CC10-IL-11 transgene $(+)$ and transgene $(-)$ littermate mice before and after exposure to $100 \% \mathrm{O}_{2}$. Lipid peroxidation was assessed by measuring the total levels of malonaldehyde and 4-hydroxyalkenals. The levels of lipid peroxidation in the lungs of transgene $(-)$ animals increased with time in $100 \% \mathrm{O}_{2}$ (Fig. 5). In contrast, the levels of lipid peroxidation in the lungs of the transgene $(+)$ mice after $72 \mathrm{~h}$ of exposure to $100 \% \mathrm{O}_{2}$ were not significantly different from the levels at baseline. In addition, the levels of lipid peroxidation in the transgene $(+)$ animals were significantly lower than those in the transgene $(-)$ animals before and at all time points after the initiation of the hyperoxic exposure (Fig. 5; $P<0.005$ at all 


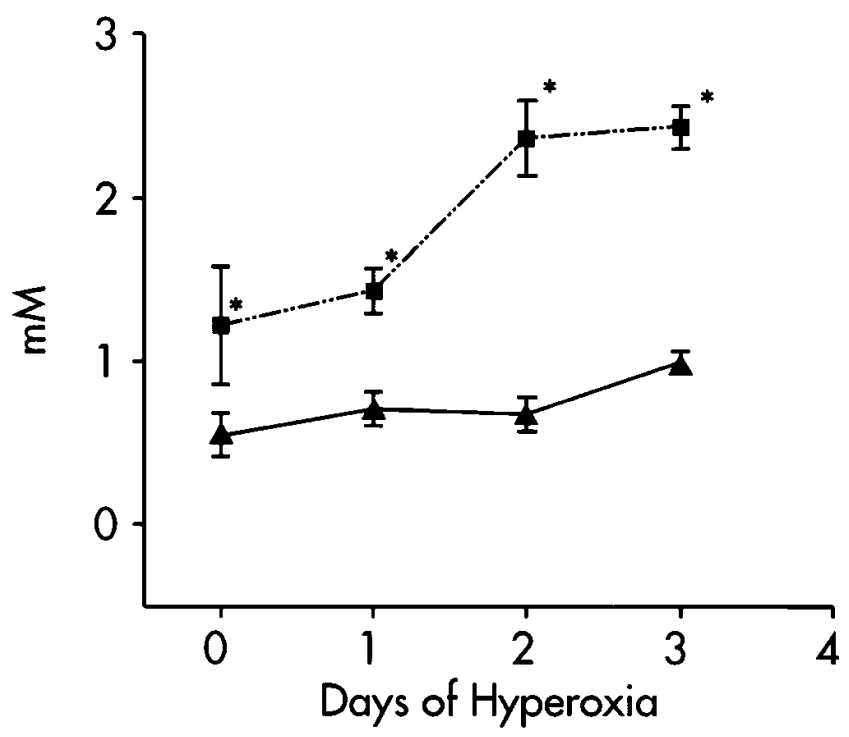

Figure 5. Lipid peroxidation in the lungs of transgene $(+)$ and transgene (-) mice. CC10-IL-11 transgene (+; triangles) and (-; squares) mice were evaluated before and after exposure to $100 \% \mathrm{O}_{2}$. Total lung lipid peroxidation was assessed as described in Methods. Values represent the mean \pm SEM of at least six animals at each time point. $(* P<0.005$ compared with transgene $[+]$ animals at corresponding time point.)

time points). This demonstrates that the levels of basal lipid peroxidation and the degree of hyperoxia-induced lipid peroxidation were significantly lower in CC10-IL-11 transgene $(+)$ animals as compared with their transgene $(-)$ littermate controls.

Effect of IL-11 on antioxidant enzymes. Aerobic biologic systems have evolved several endogenous antioxidant defense
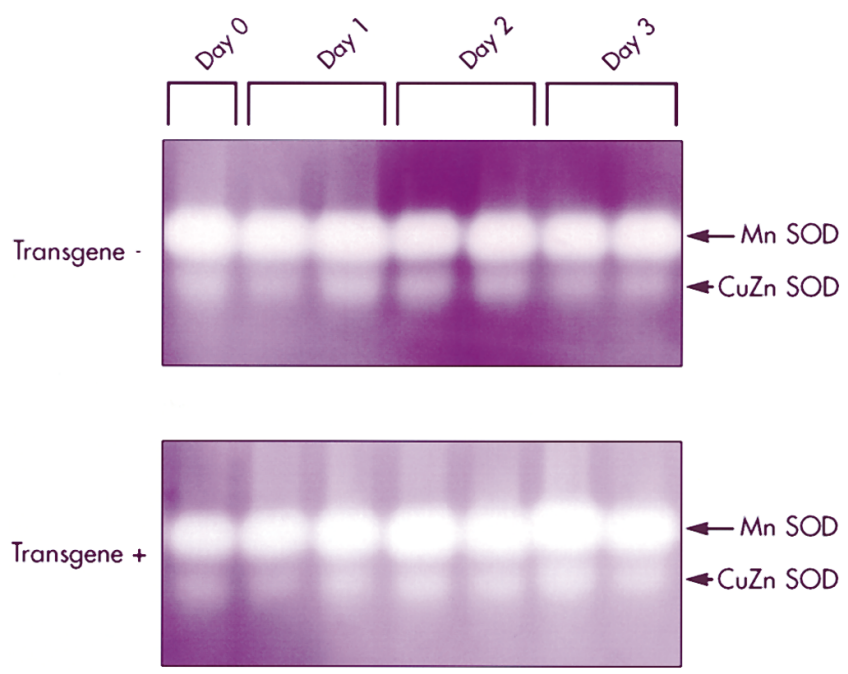

Figure 6. Mn-SOD and CuZn-SOD activities in lungs of CC10-IL-11 transgene $(+)$ and transgene $(-)$ mice. Lungs were isolated from transgene $(+)$ and transgene $(-)$ mice before and at intervals after exposure to $100 \% \mathrm{O}_{2}$. The Mn-SOD and CuZn-SOD activities in these lungs were then assessed by gel electrophoresis as described in Methods. One or two representative transgene ( - ) and transgene $(+)$ animals are illustrated at each time point. mechanisms to combat oxidative stress. These defense mechanisms include the superoxide dismutases (28), the redox cycling of glutathione (29), and catalase (30). To address the possibility that alterations in these protective pathways might be responsible for the protection induced by IL-11, we compared these pathways in the lungs of transgene $(-)$ and transgene $(+)$ mice before and after exposure to $100 \% \mathrm{O}_{2}$. Significant differences in the CuZn-SOD activities were not noted at any time point (Fig. 6). Similarly, the baseline levels of Mn-SOD activity and mRNA were similar in the lungs from transgene (-) and transgene $(+)$ mice. (Figs. 6 and 7). In contrast, the levels of Mn-SOD activity in transgene $(+)$ lungs were $\sim 1.5-2$-fold higher than the levels in transgene $(-)$ lungs after exposure to $100 \% \mathrm{O}_{2}$ for $48-72 \mathrm{~h}$ (Fig. 6). $100 \% \mathrm{O}_{2}$ caused a modest increase in whole lung MnSOD mRNA (data not shown). The magnitude of this effect, however, was small compared with the ability of IL-11 and $100 \% \mathrm{O}_{2}$ to interact in the stimulation of Mn-SOD mRNA. This interaction can be readily appreciated in Fig. 7, which demonstrates that the multiple mRNA transcripts that encode Mn-SOD are impressively augmented in lungs from transgene $(+)$ animals after $48-72 \mathrm{~h}$ of $100 \% \mathrm{O}_{2}$ exposure.

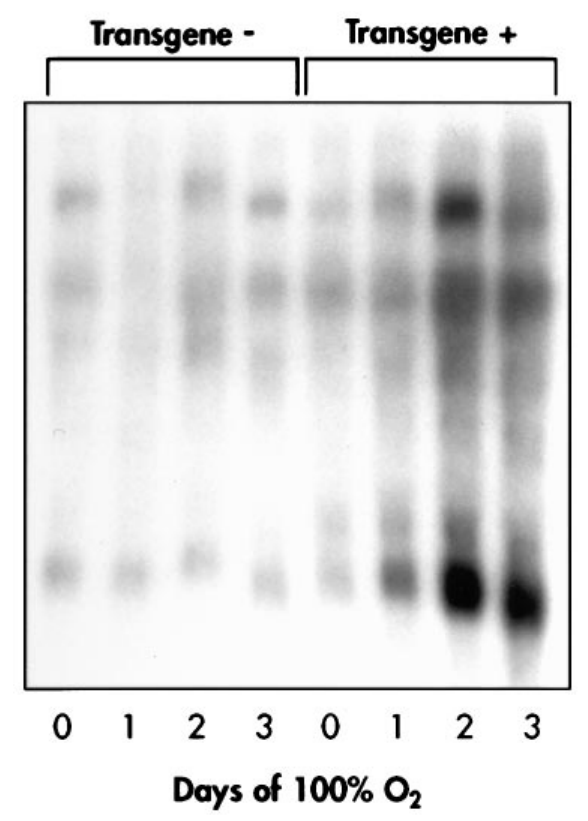

\section{Mn-SOD}

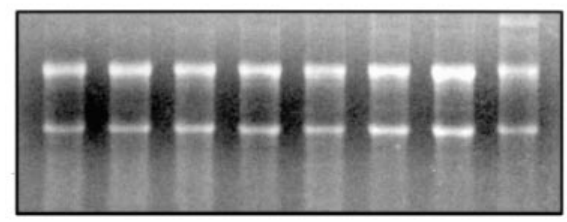

Ethidium Bromide

Figure 7. Mn-SOD mRNA in CC10-IL-11 mice. Lungs were obtained from transgene $(-)$ and $(+)$ mice before and at intervals after exposure to $100 \% \mathrm{O}_{2}$ for the noted periods of time. Total lung mRNA was isolated and Mn-SOD mRNA assessed as described in Methods. 


\section{A}
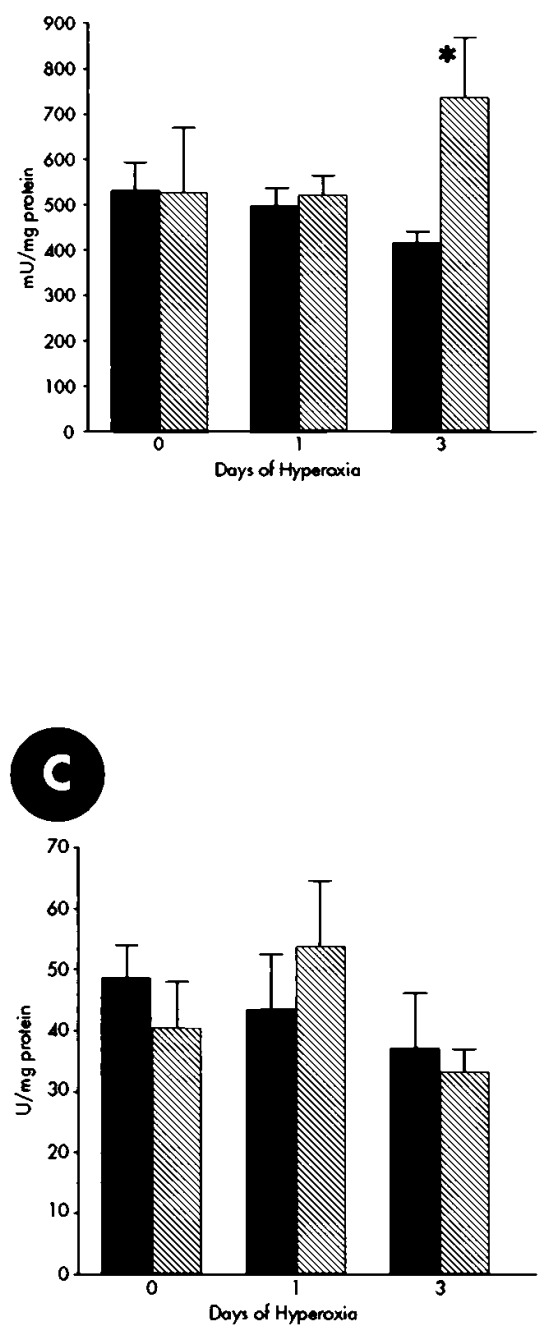

B
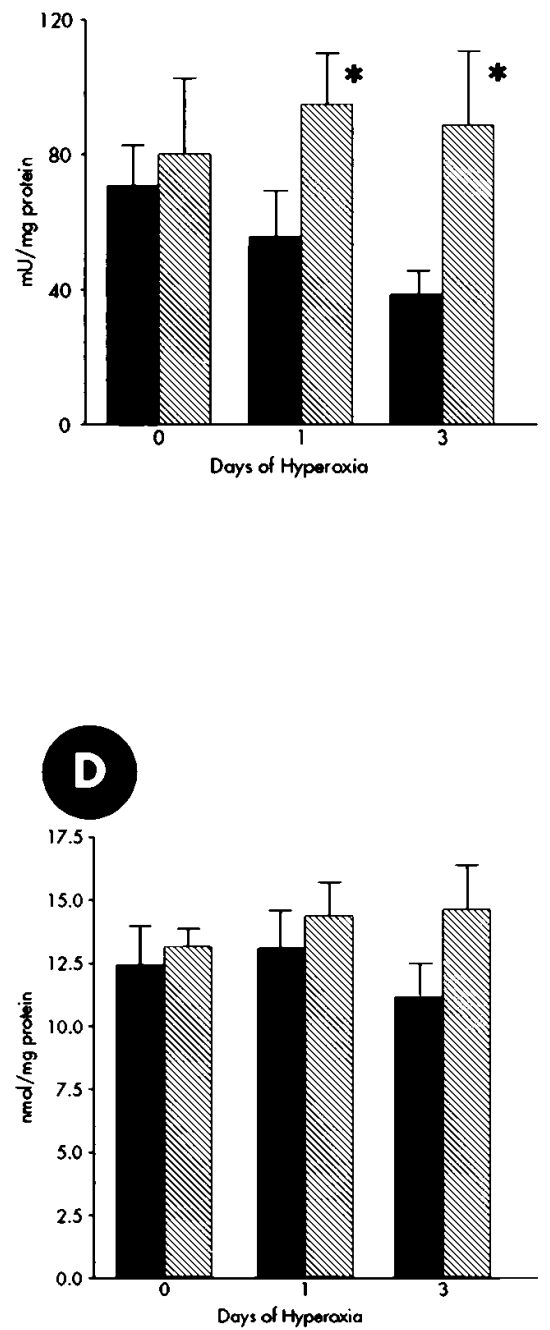

Figure 8. Antioxidant activities in transgene $(-)$ and transgene $(+)$ mice. Lungs were isolated from transgene $(+;$ hatched bars $)$ and $(-$; solid bars) mice before and at intervals after exposure to $100 \% \mathrm{O}_{2}$. Whole lung glutathione peroxidase activity $(A)$, glutathione reductase activity $(B)$, catalase activity $(C)$, and total glutathione content $(D)$ were evaluated as described in Methods. The noted values represent the mean \pm SEM of evaluations in at least six animals at each time point. $(* P<0.05$ compared with transgene [-] animals at same time point).
At baseline, the levels of total, reduced and oxidized glutathione, and the activities of catalase, glutathione peroxidase, and glutathione reductase were similar in the lungs of transgene $(+)$ and transgene $(-)$ animals (Fig. 8 and data not shown). In addition, exposure to $100 \% \mathrm{O}_{2}$ did not significantly alter the levels of total, reduced, or oxidized glutathione or the levels of catalase activity in these animals (Fig. 8 and data not shown). However, exposure to $100 \% \mathrm{O}_{2}$ decreased the glutathione reductase activity in the lungs of transgene $(-)$ but not transgene $(+)$ animals (Fig. 8). As a result the glutathione reductase activity in the lungs from the transgene $(+)$ animals was approximately twofold higher than that in the transgene $(-)$ mice after $72 \mathrm{~h}$ of $100 \% \mathrm{O}_{2}$ exposure $(P<0.05)$. Hyperoxia also augmented the glutathione peroxidase activity in lungs from transgene $(+)$ but not transgene $(-)$ animals. These changes, although statistically significant, were of modest (less than twofold) magnitude (Fig. 8).

All in all, these studies demonstrate that transgene (+) and transgene (-) animals have similar levels of CuZn-SOD and catalase activity before and after exposure to $100 \% \mathrm{O}_{2}$. They also demonstrate that IL-11 does not alter the levels of total, reduced and oxidized glutathione but does induce small increases in glutathione reductase, glutathione peroxidase, and Mn-SOD activities after $100 \% \mathrm{O}_{2}$ exposure.

Effect of IL-11 on IL-1 and tumor necrosis factor induction. When properly administered, IL-1 and TNF- $\alpha$ can protect against $\mathrm{O}_{2}$ toxicity (31-35). Thus, studies were undertaken to determine if the protective effects of IL-11 could be mediated by the ability of IL-11 to stimulate the production of these important cytokines. This was done by comparing the expression of IL-1 and TNF in the lungs of these animals before and after $\mathrm{O}_{2}$ administration. At baseline the levels of IL- $1 \beta$ and TNF in the BAL fluid of transgene $(-)$ and transgene $(+)$ mice did not differ from one another and were near the limits of detection with our assays (Fig. 9). Similarly, the basal levels of IL- $1 \beta$ and TNF mRNA in the lungs of these animals were difficult to detect with the techniques that were employed and important differences between transgene $(+)$ and $(-)$ animals could not be appreciated (data not shown). In accord with prior reports in the literature (36) $100 \% \mathrm{O}_{2}$ induced the ex- 

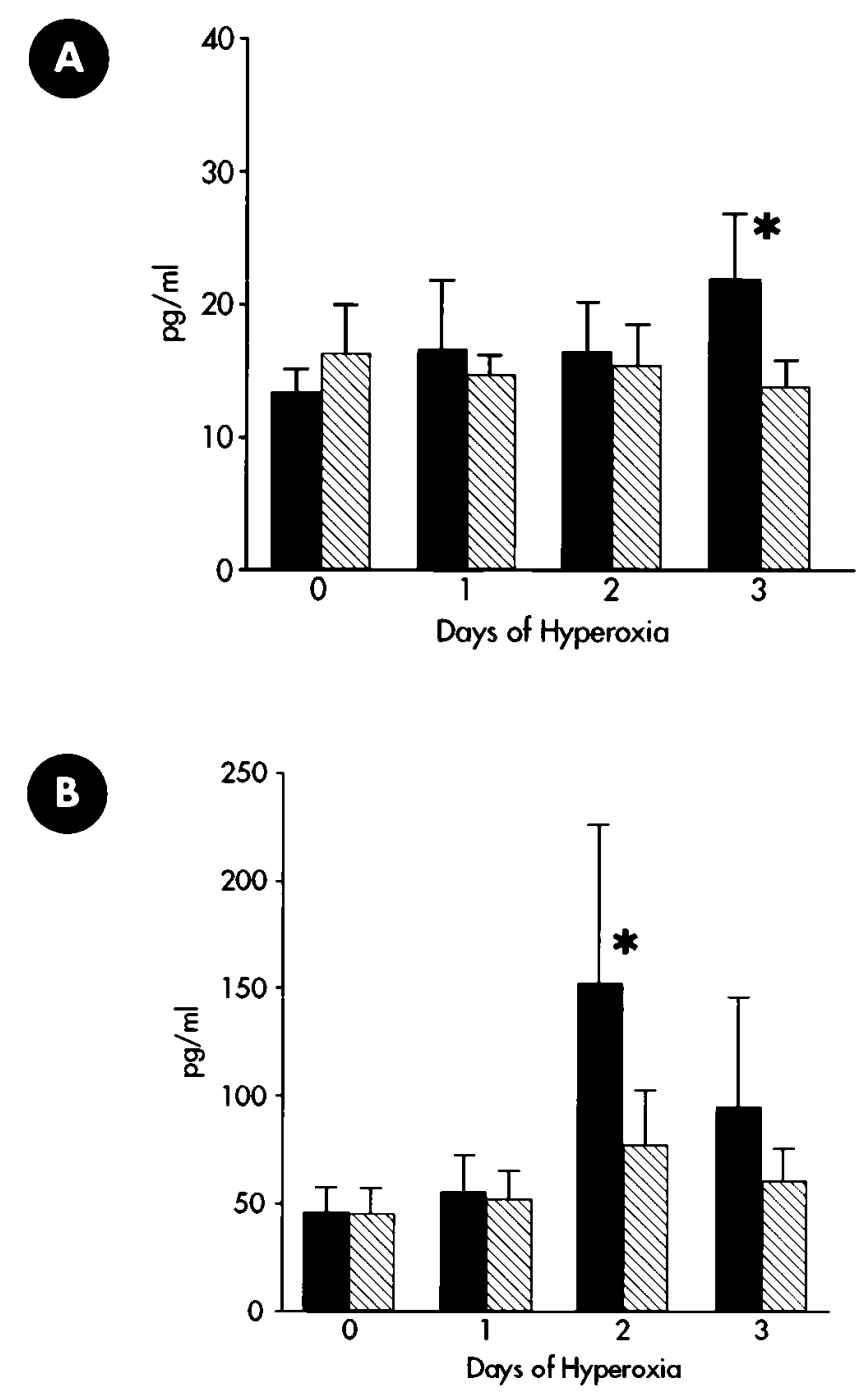

Figure 9. Quantification of the levels of IL-1 $\beta$ and TNF protein in the BAL fluid of CC10-IL-11 mice. BAL was performed on transgene $(+;$ hatched bars $)$ and transgene $(-;$ solid bars $)$ mice before and at intervals after exposure to $100 \% \mathrm{O}_{2}$. The levels of IL-1 $\beta(A)$ and TNF $(B)$ in these BAL fluids were then quantitated by ELISA. Each value represents the mean \pm SEM of determinations involving at least six animals. ( $* P<0.05$ versus transgene $[+]$ animals at same time point.)

pression of IL-1 $\beta$ and TNF mRNA and protein in the lungs from transgene (-) animals (Fig. 9 and data not shown). These responses were blunted, however, in the transgene $(+)$ animals demonstrating that IL-11 inhibits the production of IL-1 and TNF in this setting. When viewed in combination, these studies demonstrate that IL-11 does not induce the expression of IL-1 $\beta$ or TNF in a fashion that could allow these cytokines to contribute to the protective effects of IL-11 in hyperoxic pulmonary injury.

Effect of IL-11 on hyperoxia-induced DNA fragmentation. To further understand the mechanism(s) of IL-11-induced protection, TUNEL staining and DNA laddering were used to compare the levels of DNA fragmentation in the lungs of $100 \% \mathrm{O}_{2}$ exposed transgene $(-)$ and transgene $(+)$ littermate mice. The experiments performed using TUNEL staining re- vealed prominent hyperoxia-induced nuclear staining in the lungs of transgene $(-)$ animals. Nuclear staining could also be appreciated in the lungs of the transgene $(+)$ animals but at a much lower level. This difference was most prominent after $72 \mathrm{~h}$ of exposure to $100 \% \mathrm{O}_{2}$. At this time point, $55.3 \pm 5.5 \%$ of the cells in the lungs from the transgene (-) animals manifest DNA fragmentation as versus $16.5 \pm 5.5 \%$ of the cells in the lungs from the transgene $(+)$ mice $(P<0.01$; Fig. 10). Similar findings were obtained with the assays of DNA laddering since DNA fragmentation was a prominent finding in the lungs from the transgene $(-)$, but not the transgene $(+)$ mice, after $72 \mathrm{~h}$ of exposure to $100 \% \mathrm{O}_{2}$ (Fig. 11). These studies demonstrate that $100 \% \mathrm{O}_{2}$ induces impressive DNA fragmentation in normal lungs and that IL-11-induced protection in oxygen toxicity is associated with a marked diminution in this response.

Importance of morphologic alterations in IL-11-induced protection. The CC10-IL-11 mice manifest airway remodeling with subepithelial fibrosis, peribronchiolar nodules, and large alveoli $(13,15)$. Thus, studies were undertaken to determine whether these morphologic abnormalities were responsible for the protective effects of IL-11. This was done by using an inducible lung-specific overexpression transgenic system developed in our laboratory (15). This system is based on the generation of dual transgenic mice. In the first construct the CC10 promoter is used to target rtTA to the airway. In the presence of doxycycline, rtTA binds to and transcriptionally activates the second construct that contains an IL-11 cDNA. In the absence of doxycycline, dual transgene $(+)$ animals have very low to undetectable levels of BAL IL-11. Within $48 \mathrm{~h}$ of the addition of doxycycline to the animals' drinking water, significant levels of IL-11 could be appreciated.

In these experiments we compared the survival of transgene $(-)$ animals on normal water, dual transgene $(+)$ animals receiving normal water and transgene $(-)$, and dual transgene $(+)$ animals that had received water with doxycycline (dox water) for $1 \mathrm{wk}$. The 1-wk time point was chosen because we have noted previously that short periods of IL-11 production (up to $10 \mathrm{~d}$ ) in adult CC10-rtTA-hIL-11 mice did not cause significant morphologic alterations (15). In accord with our previous findings, the transgene ( - ) animals on normal water or dox water died within $72-96 \mathrm{~h}$ of the administration of $100 \% \mathrm{O}_{2}$ (Fig. 12). In addition, dual transgene $(+)$ animals receiving normal water had a modest but insignificant increase in survival, dying between $72-120 \mathrm{~h}$ after the administration of $100 \% \mathrm{O}_{2}$ (Fig. 12). In contrast, dual transgene $(+)$ animals receiving dox water manifest significantly enhanced survival in $100 \% \mathrm{O}_{2}$ with $\sim 60 \%$ of these animals surviving greater than $6 \mathrm{~d}$ and many animals surviving $7 \mathrm{~d}$ of $100 \% \mathrm{O}_{2}$ exposure $(P<0.05)$. These studies demonstrate that the impressive ability of CC10-IL-11 animals to tolerate $100 \% \mathrm{O}_{2}$ can not be attributed solely to the morphologic alterations caused by the transgenic expression of IL-11.

\section{Discussion}

To determine if IL-11 has protective effects in the setting of hyperoxic lung injury, we compared the survival and injuries induced by $100 \% \mathrm{O}_{2}$ using transgenic mice that constitutively or inducibly overexpress IL-11 in the lung and appropriate littermate controls. In these studies we demonstrate, for the first time, that IL-11 is protective in this setting. This protection manifested as enhanced survival and was associated with a significant decrease in hyperoxia-induced endothelial cell and epi- 

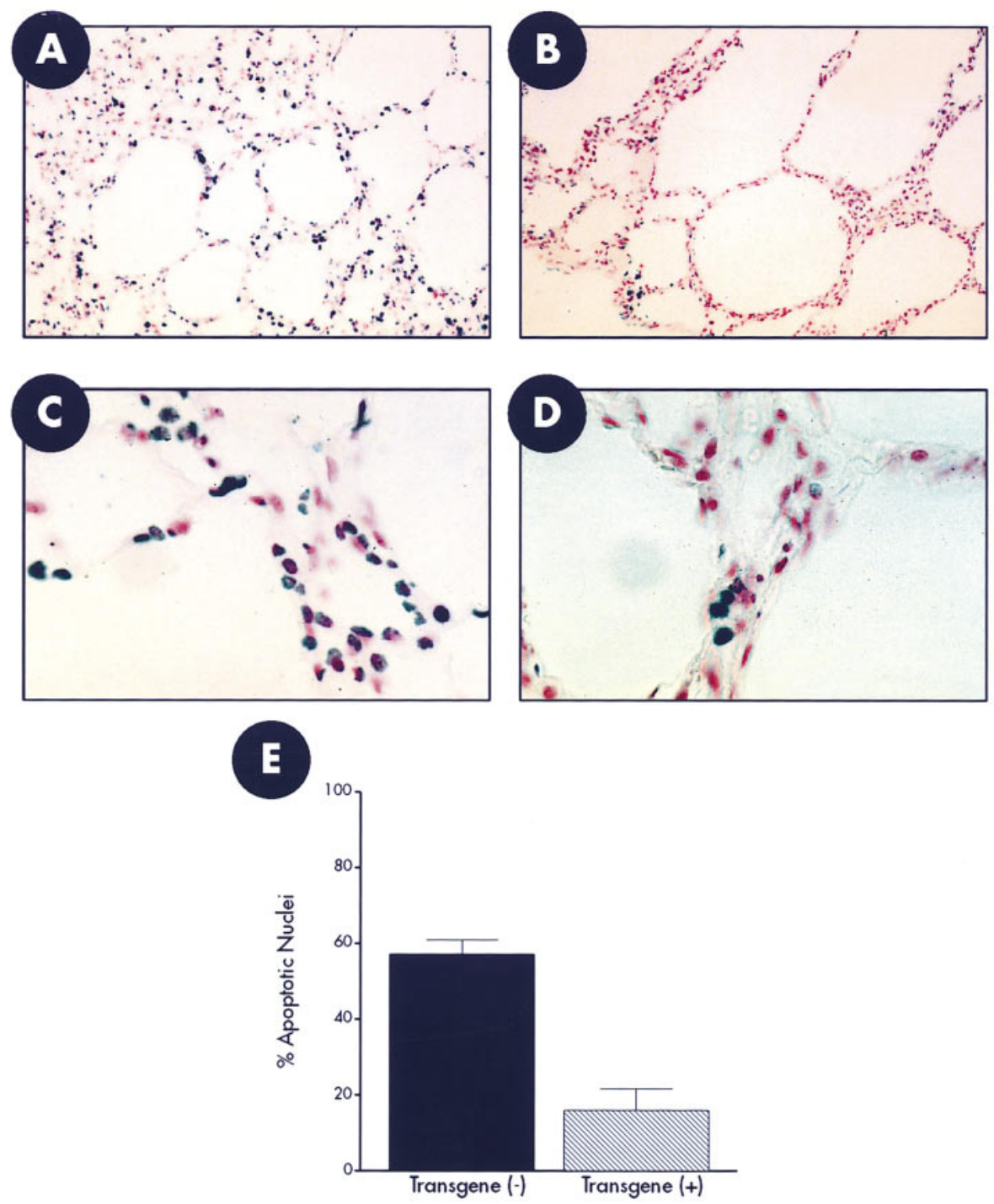

Figure 10. Effect of IL-11 on cellular DNA fragmentation. CC10-IL-11 transgene (-) and transgene $(+)$ mice were exposed to $100 \% \mathrm{O}_{2}$ for $72 \mathrm{~h}$. DNA fragmentation was then evaluated using the TUNEL assay described in Methods. $A$ and $B$ are representative photomicrographs illustrating the levels of nuclear staining in transgene (-) and $(+)$ lungs respectively at low power $(\times 31.2)$. $C$ and $D$ are representative photomicrographs illustrating the levels of nuclear staining in transgene $(-)$ and $(+)$ lungs respectively photographed at high power $(\times 125)$. The overall levels of apoptosis after $72 \mathrm{~h}$ of exposure to $100 \% \mathrm{O}_{2}$ are illustrated in $E$. The values in this panel represent the mean \pm SEM of the nuclear staining in six transgene $(+)$ and $(-)$ lungs respectively. thelial cell membrane injury, granulocyte infiltration, alveolarcapillary protein leak, and lipid peroxidation. These studies also demonstrate that IL-11 administration was not associated with significant alterations in lung catalase, or $\mathrm{Cu}-\mathrm{Zn}$ SOD activities or the levels of total, reduced or oxidized glutathione. IL-11 expression was, however, associated with small alterations in lung Mn-SOD, glutathione reductase and glutathione peroxidase activities and decreased hyperoxia-induced TNF and IL-1 production. Importantly, they also demonstrate that hyperoxia-induced lung injury is associated with impressive levels of respiratory cell death and DNA fragmentation and that IL-11 overexpression markedly diminishes this cellular response in pulmonary structures.

An interesting question is raised in these studies that relates to the sites of hyperoxic injury and IL-11 production in our mice. The alveolar epithelium and endothelium are presumed to be the cells that are most sensitive to hyperoxic injury. The CC10 promoter, in contrast, has been presumed to target proteins to airway Clara cells. Thus, it is surprising that CC10 promoter-driven IL-11 confers protection in the setting of hyperoxia. There are, however, at least two ways that IL-11 could reach the alveolus. The first relates to the significant levels of IL-11 that can be found in the BAL fluid of these transgenic animals (13). It is possible that IL-11 flows distally into the alveolus where it mediates its protective effects. Alternatively, the CC10 promoter may not be absolutely specific in its protein targeting. In some circumstances, CC10 can also express weakly in alveolar epithelial cells. Thus, IL-11 may also be produced directly at sites of alveolar injury. Support for the latter possibility comes from studies from our laboratory demonstrating that CC10-IL-11 transgene $(+)$ mice have defects in alveolar development compatible with local IL-11 elaboration (15).

A characteristic pattern of injury occurs in animals exposed to a hyperoxic environment. It includes endothelial and epithelial membrane damage, enhanced alveolar-capillary permeability with pulmonary edema, membrane lipid peroxidation, and the recruitment of granulocytes to respiratory structures $(23,24,37)$. These alterations are felt to result, in great extent, from the excessive production/accumulation of oxygen free radicals (38). Since IL-11 ameliorated each of these manifestations, studies were undertaken to determine whether the ef- 


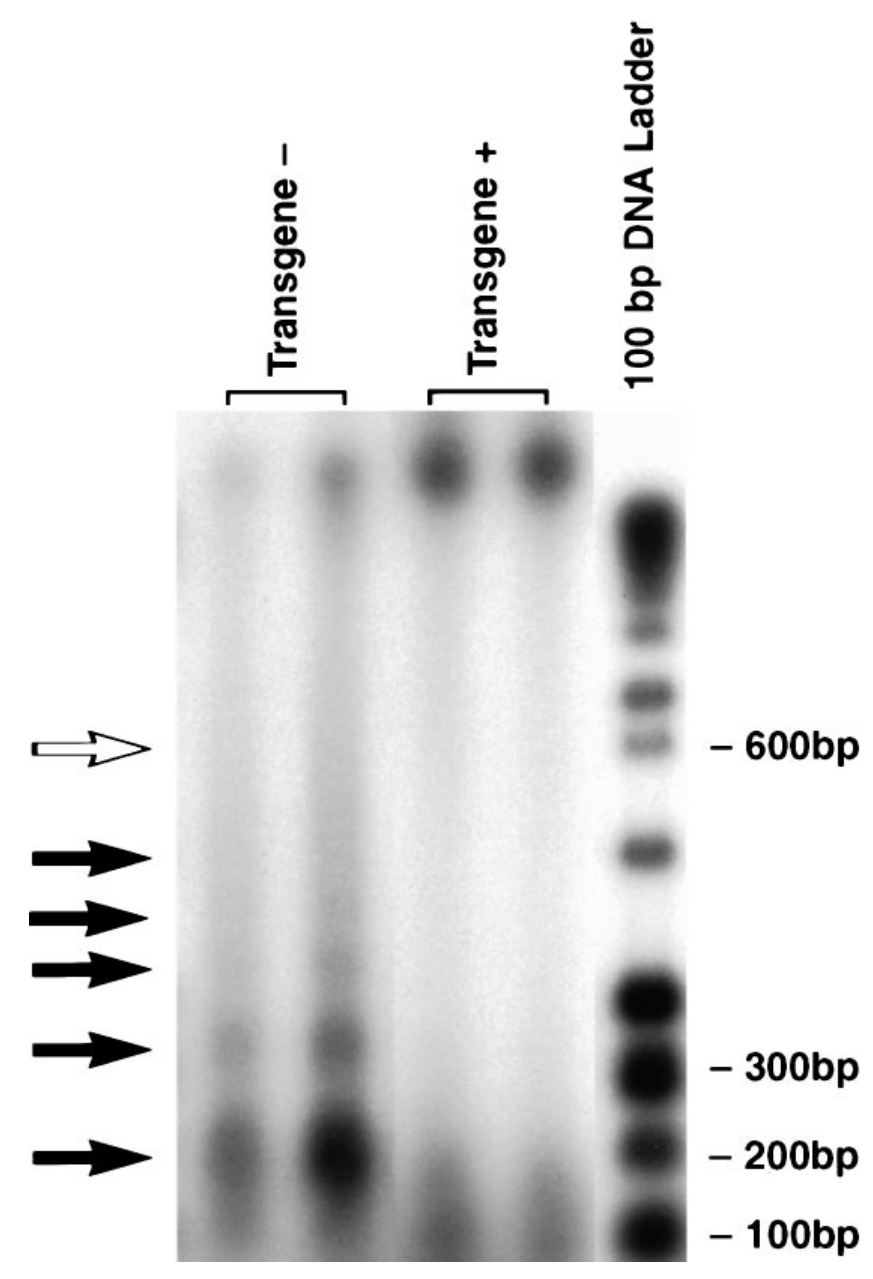

Figure 11. Comparison of DNA fragmentation in transgene $(-)$ and transgene $(+)$ mice induced by $100 \% \mathrm{O}_{2}$. CC10-IL-11 transgene $(+)$ mice and transgene $(-)$ littermate controls were exposed to $100 \% \mathrm{O}_{2}$ for $72 \mathrm{~h}$. Their lungs were then removed, total lung DNA was isolated and DNA laddering was assessed as described in Methods. DNA from two representative transgene $(-)$ and transgene $(+)$ mice are shown. The DNA sizing ladder is in the right most column. Sites of prominent DNA fragments are highlighted with the solid arrows. The hollow arrow highlights a DNA fragment that can be appreciated with a longer autoradiographic exposure.

fects of IL-11 could be mediated by IL-11-induced alterations in respiratory antioxidant defense mechanisms. The SODs are an important first line of oxidative defense (39), which dismutate superoxide anions to $\mathrm{H}_{2} \mathrm{O}_{2} \cdot \mathrm{H}_{2} \mathrm{O}_{2}$ is then neutralized to water by catalase (28). At baseline and after $100 \% \mathrm{O}_{2}$ exposure, similar levels of catalase and $\mathrm{CuZn-SOD}$ activities were noted in lungs from transgene (+) and transgene (-) animals. At baseline the levels of Mn-SOD activity were also similar in the lungs from transgene $(-)$ and transgene $(+)$ mice. After exposure to $100 \% \mathrm{O}_{2}$ the levels of $\mathrm{Mn}$-SOD activity in lungs from transgene $(+)$ animals were slightly higher than in the lungs from transgene (-) mice. IL-11 also interacted with hyperoxia to cause a significant increase in lung Mn-SOD mRNA accumulation. When viewed in combination, these studies demonstrate that the effects of IL-11, in this system, are mediated by a mechanism that is largely independent of al- terations in lung CuZn-SOD and catalase and associated with small-modest alterations in Mn-SOD. It is important to point out, however, that these studies do not rule out the possibility that there are significant alterations in these antioxidants in small numbers of cells in transgene $(+)$ mice that can not be detected in our assays. The biologic significance of the $\mathrm{Mn}$ SOD alterations must also be questioned since in accord with the known translational and post-translational regulation of Mn-SOD (40), we noted that IL-11 plus hyperoxia caused impressive increases in Mn-SOD mRNA and only small alterations in Mn-SOD activity. Additional experimentation will be required to address both of these issues.

Another important defense against oxidative stress is the redox cycling of glutathione (29). Glutathione reduces $\mathrm{H}_{2} \mathrm{O}_{2}$, eliminates several lipid peroxides, and reactivates antioxidant enzymes $(41,42)$. Cells normally maintain a high ratio of reduced to oxidized glutathione via the activities of glutathione peroxidase and glutathione reductase. In our studies the activities of glutathione reductase and glutathione peroxidase were similar in transgene $(-)$ and transgene $(+)$ mice at baseline. In contrast, the activities of both enzymes were increased in transgene $(+)$ as versus transgene $(-)$ mice after $72 \mathrm{~h}$ of $100 \%$ $\mathrm{O}_{2}$ exposure. The importance of these alterations is open to question because the magnitude of each alteration was modest, and the alterations were not associated with a statistically significant difference in the pulmonary GSH/GSSG ratios. In addition, the alterations in glutathione peroxidase, the ratelimiting enzyme in this pathway, were not seen until the animals received $100 \% \mathrm{O}_{2}$ for $72 \mathrm{~h}$. Hyperoxia-induced injury and IL-11-mediated protection were readily appreciated after shorter (24-48 h) exposures to $100 \% \mathrm{O}_{2}$. These findings, however, cannot be totally discounted since increases in glutathione-peroxidase activity have been implicated in the resistance to hyperoxia seen in older versus younger rodents (43) and increases in glutathione reductase may play a role in endotoxin induced resistance to $\mathrm{O}_{2}(44)$.

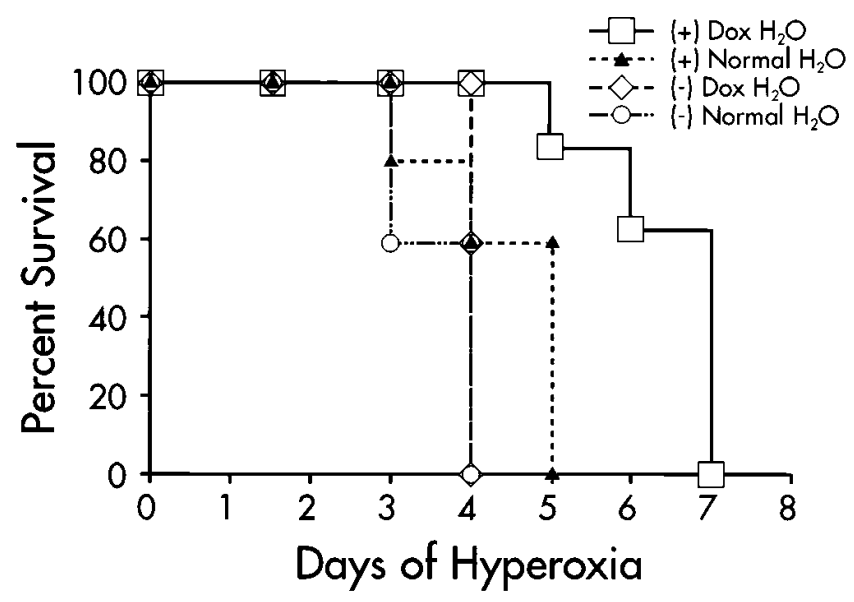

Figure 12. Survival of CC10-rtTA-hIL-11 transgenic mice in $100 \%$ $\mathrm{O}_{2}$. CC10-rtTA-hIL-11 transgenic mice and appropriate controls were exposed to $100 \% \mathrm{O}_{2}$ and survival was evaluated as described in Methods. Comparisons are made of transgene (-) animals receiving normal water (circles), transgene (-) animals receiving Dox $\mathrm{H}_{2} \mathrm{O}($ diamonds), dual transgene (+) animals receiving normal $\mathrm{H}_{2} \mathrm{O}$ (triangles) and dual transgene $(+)$ animals receiving Dox $\mathrm{H}_{2} \mathrm{O}$ (squares). The noted values represent the percentage survival of 12 animals at each time point. 
Exogenously administered TNF and IL- 1 have both been shown to increase pulmonary oxygen tolerance. The protective effects of these cytokines are associated with the induction of Mn-SOD but not CuZn-SOD in vivo (31-33, 45). To determine if the protective effects of IL-11 are mediated via the ability of IL-11 to induce the production of these cytokines, the levels of IL-1 and TNF in the BAL fluid of transgene (+) and transgene $(-)$ animals at baseline and after $100 \% \mathrm{O}_{2}$ exposure were quantitated. IL-11 did not stimulate IL-1 or TNF production in transgene $(+)$ animals. In keeping with the findings of others $(36,46,47), 100 \% \mathrm{O}_{2}$ stimulated pulmonary TNF and IL-1 $\beta$ mRNA and protein in transgene $(-)$ animals. Interestingly, IL-11 was a potent inhibitor of these inductive responses. This is in keeping with prior reports from our laboratory (12) and others (48) demonstrating that IL-11 is a potent inhibitor of macrophage TNF and IL-1 elaboration. These studies demonstrate that the protective effects of IL-11 are not mediated via the ability of IL-11 to stimulate the production of IL-1 or TNF. They do, however, raise the possibility that the protective effect of IL-11 may be mediated, in part, by the ability of IL-11 to inhibit $100 \% \mathrm{O}_{2}$-induced TNF elaboration. The latter will require additional investigation, however, since there is controversy in the literature with some investigators reporting that $\mathrm{O}_{2}$-induced TNF is involved in (36) or not involved in (46) the pathogenesis of pulmonary oxygen toxicity.

Neutrophil infiltration in hyperoxic pulmonary injury is well described (49). This inflammatory cell migration coincides with endothelial cell injury suggesting that pulmonary oxygen toxicity is, in part, neutrophil-mediated $(27,50)$. An interesting finding in our studies was the ability of IL-11 to inhibit neutrophil infiltration into pulmonary structures after exposure to $100 \%$ oxygen. This observation suggests that the protective effects of IL-11 may be mediated, at least in part, by the ability of IL-11 to inhibit neutrophil influx. This speculation is in accord with a variety of other therapeutic interventions, which improve oxygen tolerance while diminishing pulmonary neutrophil accumulation $(51,52)$. In evaluating this hypothesis it is important to keep in mind that cause and effect are difficult to differentiate in these experiments. IL-11 may inhibit neutrophil recruitment, which may decrease lung injury. Alternatively, IL-11 may decrease lung injury that can, in turn, decrease neutrophil recruitment. It is also important to appreciate that protective effects of IL-11 can be seen in the absence of neutrophil infiltration. For example, the levels of lipid peroxidation in the lungs of transgene $(+)$ animals were significantly lower than in the lungs of transgene $(-)$ animals before $100 \% \mathrm{O}_{2}$ was administered. Thus, even if IL-11-mediated inhibition of neutrophil infiltration is biologically important, it is likely to be only one of a number of processes mediating the protective effects of IL-11 in this injury state.

In most forms of tissue injury cells die via necrosis (53). In necrosis there are early changes in mitochondrial shape and function and the cell rapidly becomes unable to maintain internal homeostasis. As a result, the cell swells and bursts and its contents are spilled into surrounding tissue spaces where they evoke an inflammatory response (53). In contrast, apoptosis, or programmed cell death, is considered to be an operationally and mechanistically distinct cell death response (53-55). Cells underlying apoptosis have a characteristic morphologic appearance and activated endogenous endonucleases that cleave host chromatin into oligonucleosome-length DNA fragments $(54,55)$. This characteristic DNA fragmentation pattern has been used as a marker for the activation of apoptotic pathways in vivo and in vitro $(38,53-56)$. To further understand the mechanism(s) by which hyperoxia induces pulmonary injury, studies were undertaken to determine whether DNA fragmentation could be detected in the lungs of $100 \% \mathrm{O}_{2}$ exposed transgene (-) animals. These studies demonstrated impressive levels of DNA fragmentation with both the TUNEL and DNA laddering techniques. These findings are in accord with the observations of others (38) and support the contention that apoptosis plays an important role in the pathogenesis of hyperoxic lung injury (38). This conclusion must be looked at with caution, however, because it has been noted recently that the distinction between necrosis and apoptosis may not be as crisp as previously thought. Specifically, endonuclease activation and apoptosis-like DNA laddering can be seen in cells undergoing necrosis $(55,56)$ and known inducers of apoptosis (such as Fas antibodies) can cause cells to die via necrosis in well-defined circumstances (56). In addition, the same population of cells can be induced to undergo apoptosis or necrosis by different doses of the same triggering stimulus (53). Thus, additional investigation will be required to define the extent to which apoptosis and/or necrosis contribute to the DNA fragmentation that was noted and the overall pathogenesis of oxygen toxicity.

An interesting finding in our studies was the demonstration that IL-11 diminished DNA fragmentation in the lungs of mice exposed to $100 \% \mathrm{O}_{2}$. This is in keeping with prior reports demonstrating that IL-11 decreases apoptosis in interstitial crypt cells after cytoablative therapy (54) and bowel ischemia (11). These studies are the first to demonstrate that oxygen toxicity is ameliorated by interventions that simultaneously alter DNA degradation. These data do not allow us to state with certainty that the improved survival of transgene $(+)$ animals in $100 \%$ $\mathrm{O}_{2}$ is the result of the effects of IL-11 on DNA degradation. It is tempting to speculate, however, that interventions that alter cellular endonuclease activity can modify the natural history of animals in hyperoxic environments. The mechanism(s) by which IL-11 induces protection and decreases DNA fragmentation are poorly understood. The ability of IL-11 to inhibit p53 protein (11) and/or epithelial cell proliferation (57) might be important in this protection. Alternatively, IL-11 might regulate the expression or function of apoptosis regulating moieties such as Bcl-2 $(53,54)$. This is a particularly enticing hypothesis since $\mathrm{Bcl}-2$ has been shown to inhibit necrosis as well as apoptosis $(53,54,58)$.

The clinical decision to administer high concentrations of oxygen to a patient is made when the perceived benefits to the patient that result from enhanced tissue oxygen delivery exceed the pulmonary and other visceral injuries caused by the intervention. The benefits of this administration are seen on a daily basis in patients with readily reversible pathologies such as cardiogenic pulmonary edema, antibiotic sensitive pneumonia, and transient pulmonary atelectasis, mucus plugging, bronchospasm, and vascular obstruction. The use of hyperoxic gas mixtures becomes problematic, however, in conditions like acute respiratory distress syndrome and other chronic pulmonary pathologies where the time course of the disease mandates prolonged oxygen administration. Our studies demonstrate, for the first time, that IL-11 has the potential to be useful in this setting since it markedly augments survival and diminishes $100 \% \mathrm{O}_{2}$-induced pulmonary injury. They also demonstrate that this IL-11-induced protective effect is likely multifactoral in pathogenesis with IL-11 inducing small changes in 
lung antioxidant defenses, inhibiting hyperoxia-induced IL-1 and TNF elaboration and neutrophil infiltration, and markedly diminishing $100 \% \mathrm{O}_{2}$-induced pulmonary cell death and DNA fragmentation. Initial human studies have shown that IL-11 can be safely administered in pharmacologic concentrations and that $\mathrm{ng} / \mathrm{ml}$ concentrations of IL-11 can be detected in serum after the administration of $\mathrm{mg} / \mathrm{kg}$ doses of IL-11 protein (11). Studies from our laboratory and others have also demonstrated that IL-11 also has anti-inflammatory effects that may be the result of its ability to inhibit macrophage IL-1, TNF, and IL-12 production $(12,48,59)$. This contrasts impressively with the effects of agents such as IL-1 and TNF, which also have the ability to enhance oxygen tolerance $(31-33,45)$, but which do so with a much lower therapeutic index. All in all, these studies suggest that IL-11 is a useful agent that can shift the risk-benefit analysis of chronic hyperoxic oxygen administration in favor of the patient. Further investigation of the potential prophylactic and therapeutic utility of IL-11 in the setting of hyperoxia-induced lung injury and other oxidant-induced injury states is warranted.

\section{Acknowledgments}

The authors wish to thank the investigators that provided the reagents, Mr. Yang Wu for his expert technical assistance, and Ms. Kathleen Bertier for her excellent secretarial assistance.

This work was supported by grants HL-41216, HL-36708, and AI34953 (J.A. Elias). Dr. Waxman is a Parker B. Francis Scholar.

\section{References}

1. Crapo, J.D. 1986. Morphologic changes in pulmonary oxygen toxicity. Annu. Rev. Physiol. 48:721-731.

2. Crapo, J.D., B.E. Barry, H.A. Foscue, and J. Shelburne. 1980. Structural and biochemical changes in rat lungs occurring during exposure to lethal and adaptive doses of oxygen. Am. Rev. Respir. Dis. 122:123-143.

3. Hayatdavoudi, G., J.J. O'Neil, and E. Barry. 1981. Pulmonary injury in rats following continuous exposure to $60 \% \mathrm{O}_{2}$ for 7 days. J. Appl. Physiol. 51: $1220-1231$.

4. DelMaestro, R., F. Bjork, and K.E. Arfors. 1981. Increase in microvascular permeability induced by enzymatically generated free radicals. Microvasc. Res. 22:239-254.

5. Jenkinson, S.G. 1982. Pulmonary oxygen toxicity. Clin. Chest Med. 3: 109-119.

6. Paul, S.R., F. Bennett, J.A. Calvetti, K. Kelleher, C.R. Wood, R.M. O'Hara, Jr., A.C. Leary, B. Sibley, S.C. Clark, D.A. Williams, and Y.-C. Yang. 1990. Molecular cloning of a cDNA encoding IL-11, a stromal cell derived lymphopoietic cytokine. Proc. Natl. Acad. Sci. USA. 87:7512-7516.

7. Du, X.X., and D.A. Williams. 1994. Interleukin-11: a multifunctional growth factor derived from the hematopoietic microenvironment. Blood. 83: 2023-2030.

8. Du, X.X., C.M. Doerschuk, A. Orazi, and D.A. Williams. 1994. A bone marrow stromal-derived growth factor, interleukin-11, stimulates recovery of small intestinal mucosal cells after cytoablative therapy. Blood. 83:33-37.

9. Keith, J.C., Jr., L. Albert, S.T. Sonis, C.J. Pfeiffer, and R.G. Schaub. 1994. IL-11, a pleiotropic cytokine: exciting new effects of IL-11 on gastrointestinal mucosal biology. Stem Cells (Dayton). 12(Suppl.):79-89.

10. Qiu, B.S., C.J. Pfeiffer, and J.C. Keith. 1996. Protection by recombinant human interleukin-11 against experimental TNB-induced colitis in rats. Dig. Dis. Sci. 41:1625-1630.

11. Du, X., O. Liu, Z. Yang, A. Orazi, F.J. Rescorla, J.L. Grosfeld, and D.A. Williams. 1997. Protective effects of interleukin-11 in a murine model of ischemic bowel necrosis. Am. J. Physiol. 272:G545-G552.

12. Redlich, C.A., X. Gao, S. Rockwell, M. Kelly, and J.A. Elias. 1996. IL-11 enhances survival and decreases TNF production after radiation induced thoracic injury. J. Immunol. 157:1705-1710.

13. Tang, W., G. Geba, T. Zheng, P. Ray, R. Homer, C. Kuhn, R. Flavell, and J. Elias. 1996. Targeted expression of IL-11 in the murine airway causes airways obstruction, bronchial remodeling, and lymphocytic inflammation. J. Clin. Invest. 98:2845-2853.

14. Cruikshank, W.W., D.M. Center, N. Nisar, M. Wu, B. Natke, A.C. Theodore, and H. Kornfeld. 1994. Molecular and functional analysis of a lympho- cyte chemoattractant factor: association of biologic function with CD4 expression. Proc. Natl. Acad. Sci. USA. 91:5109-5113.

15. Ray, P., W. Tang, P. Wang, R. Homer, C. Kuhn, R.A. Flavell, and J.A. Elias. 1997. Regulated overexpression of interleukin-11 in the lung: use to dissociate development-dependent and independent phenotypes. J. Clin. Invest. 100:2501-2511.

16. Gossen, M., S. Freundlieb, G. Bender, G. Muller, W. Hillen, and H. Bujard. 1995. Transcriptional activation by tetracyclines in mammalian cells. Science. 268:1766-1769.

17. Esterbauer, H., and K.H. Cheeseman. 1990. Determination of aldehydic lipid peroxidation products: malonaldehyde and 4-hydroxynonenal. Methods Enzymol. 186:407-421.

18. Beauchamp, C., and I. Fridovich. 1971. Superoxide dismustase: improved assays and an assay applicable to acrylamide gels. Anal. Biochem. 44: 276-287.

19. Griffith, O.W. 1980. Determination of glutathione and glutathione disulfide using glutathione reductase and 2-vinylpyridine. Ann. Biochem. 106:207-212.

20. Aebi, H. 1984. Catalase in vitro. Methods Enzymol. 105:121-126.

21. Flohe, L., and W.A. Gunzler. 1984. Assays of glutathione peroxidase. Methods Enzymol. 105:114-121.

22. Bellomo, G., F. Mirabelli, D. DiMonte, P. Richelmi, H. Thor, C. Orrenius, and S. Orrenius. 1987. Formation and reduction of glutathione-protein mixed disulfides during oxidative stress. Biochemistry and Pharmacology. 36 1313-1320.

23. Smith, L.J. 1985. Hyperoxic lung injury: Biochemical, cellular, and morphologic characterization in the mouse. J. Lab. Clin. Med. 106:269-278.

24. Adamson, I.Y.R., D.H. Bowden, and J.P. Wyatt. 1970. Oxygen poisoning in mice. Ultrastructural and surfactant studies during exposure and recovery. Arch. Pathol. 90:463-472.

25. Hinshaw, D.B., J.M. Burger, B.C. Armstrong, and P.A. Hyslop. 1989 Mechanism of endothelial cell shape change in oxidant injury. J. Surgery. 46: 339-349.

26. Davis, W.B., S.I. Rennard, P.B. Bitterman, J.E. Gadek, X.H. Sun, M Wewers, B.A. Keogh, and R.G. Crystal. 1983. Pulmonary oxygen toxicity. Bronchoalveolar lavage demonstration of early parameters of alveolitis. Chest. 83(Suppl.):35S.

27. Fox, R.B., J.R. Hoidal, D.M. Brown, and J.E. Repine. 1981. Pulmonary inflammation due to oxygen toxicity: involvement of chemotactic factors and polymorphonuclear leukocytes. Am. Rev. Respir. Dis. 123:521-523.

28. Risberg, B., L. Smith, and P. Ortenwall. 1991. Oxygen radicals and lung injury. Acta Anesthesiol. Scand. 35:106-118.

29. Sies, H. 1991. Oxidative stress: from basic research to clinical application. Am. J. Med. 91:31S-38S.

30. Heffner, J.E., and J.E. Repine. 1989. Pulmonary strategies of antioxidant defense. Am. Rev. Respir. Dis. 140:531-554.

31. Visner, G.A., S.E. Chesrown, J. Monnier, U.S. Ryan, and H.S. Nick. 1992. Regulation of manganese superoxide dismutase: IL-1 and TNF induction in pulmonary artery and microvascular endothelial cells. Biochem. Biophys. Res. Commun. 188:453-462.

32. Tsan, M.-F., J.E. White, P.J. Del Vecchio, and J.B. Shaffer. 1992. IL-6 enhances TNF- $\alpha$ and IL-1 induced increase in Mn superoxide dismutase mRNA and $\mathrm{O}_{2}$ tolerance. Am. J. Physiol. 263:L22-L26.

33. Tsan, M.F., C.Y. Lee, and J.E. White. 1991. Interleukin 1 protects rats against oxygen toxicity. J. Appl. Physiol. 71:688-697.

34. Tsan, M.F., and J.E. White. 1994. Interleukin-1alpha induced protection against pulmonary oxygen toxicity [letter]. Am. J. Physiol. 266:L316-L317.

35. Ono, M., H. Kohda, T. Kawaguchi, O. Motoyuki, C. Sekiya, M. Namiki, A. Takeyasu, and N. Taniguchi. 1992. Induction of Mn-superoxide dismutase by tumor necrosis factor, interleukin-1 and interleukin-6 in human hepatoma cells. Biochem. Biophys. Res. Commun. 182:1100-1107.

36. Tsan, M.F., J.E. White, P.B. Michelsen, and G.H. Wong. 1995. Pulmonary $\mathrm{O}_{2}$ toxicity: role of endogenous tumor necrosis factor. Exp. Lung Res. 21: 589-597.

37. Tappel, A. 1973. Lipid peroxidation damage to cell components. Fed. Proc. 32:1870-1881.

38. Kazzaz, J.A., J. Xu, T.A. Palaia, L. Mantell, A.M. Fein, and S. Horowitz. 1996. Cellular oxygen toxicity. Oxidant injury without apoptosis. J. Biol. Chem. 271:15182-15186.

39. Freeman, B.A., and J.D. Crapo. 1982. Free radicals and tissue injury. Lab. Invest. 47:412-426.

40. Ho, Y., M. Dey, and J.D. Crapo. 1996. Antioxidant enzyme expression in rat lungs during hyperoxia. Am. J. Physiol. 270:L810-L818.

41. Gaullier, J.M., P. Lafontant, A. Valla, M. Bazin, M. Giraud, and R. Santus. 1994. Glutathione peroxidase and glutathione reductase activities towards glutathione derived antioxidants. Biochem. Biophys. Res. Commun. 203:16681674 .

42. Chaudiene, Z., and A.L. Tappel. 1983. Purification and characterization of selenium-glutathione peroxidase from hamster liver. Arch. Biochem. Biophys. 226:448-457.

43. Canada, A.T., L.A. Herman, and S.L. Young. 1995. An age-related difference in hyperoxia lethality: role of lung antioxidant defense mechanisms. Am. J Physiol. 268:L539-L545. 
44. Hamburg, D.C., H. Tonoki, S.E. Welty, R.S. Geske, C.A. Montgomery, and T.N. Hansen. 1994. Endotoxin induces glutathione reductase activity in lungs of mice. Pediatr. Res. 35:311-315.

45. Lee, C.Y., J.N. Pastore, G. Tang, and M.F. Tsan. 1994. Cellular distribution of pulmonary $\mathrm{Mn}$ and $\mathrm{CuZn}$ superoxide dismutase: effect of hyperoxia and interleukin-1. J. Histochem. Cytochem. 42:1201-1205.

46. Brazzone, C., F. Tacchini-Cottier, C. Vesin, A. Rochat, and P. Piguet. 1996. Hyperoxia induces platelet activation and lung sequestration: an event dependent on tumor necrosis factor-alpha and CD11a. Am. J. Respir. Cell Mol. Biol. 15:107-114.

47. O'Brien-Ladner, A.R., M.E. Nelson, B. Cowley, Jr., K. Bailey, and L.J. Wesselius. 1995. Hyperoxia amplifies TNF-alpha production in LPS-stimulated human alveolar macrophages. Am. J. Respir. Cell Mol. Biol. 12:275-279.

48. Trepicchio, W.L., M. Bozza, G. Pedneault, and A.J. Dorner. 1996. Recombinant human IL-11 attenuates the inflammatory response through downregulation of proinflammatory cytokine release and nitric oxide production. $J$. Immunol. 157:3627-3634.

49. Keeney, S.E., M.J. Mathews, A.K. Haque, and F.C. Schmalstieg. 1995. Comparison of pulmonary neutrophils in the adult and neonatal rat after hyperoxia. Pediatr. Res. 38:857-863.

50. Keeney, S.E., M.J. Mathews, A.K. Haque, H.E. Rudloff, and F.C. Schmalstieg. 1994. Oxygen-induced lung injury in the guinea pig proceeds through CD18-independent mechanisms. Am. J. Respir. Crit. Care Med. 149: 311-319.

51. Piantadosi, C.A., P.J. Fracica, F.G. Duhaylongsod, Y.C. Huang, K.E.
Welty-Wolf, J.D. Crapo, and S.L. Young. 1995. Artificial surfactant attenuates hyperoxic lung injury in primates. II. Morphometric analysis. J. Appl. Physiol. 78:1823-1831.

52. Mikawa, K., K. Nishina, N. Maekawa, and H. Obara. 1995. Attenuation of hyperoxic lung injury in rabbits with superoxide dismutase: effects on inflammatory mediators. Acta Anaesthesiol. Scand. 39:317-322.

53. Cohen, J.J. 1996. Apoptosis and its regulation. Adv. Exp. Med. Biol. 406:11-20.

54. Kroemer, G., P. Petit, N. Zamzami, J.L. Vayssiere, and B. Mignotte. 1995. The biochemistry of programmed cell death. FASEB J. 9:1277-1287.

55. Ueda, N., P.D. Walker, S.M. Hsu, and S.V. Shah. 1995. Activation of a $15-\mathrm{kDa}$ endonuclease in hypoxia/reoxygenation injury without morphologic features of apoptosis. Proc. Natl. Acad. Sci. USA. 92:7202-7206.

56. Dong, Z., P. Saikumar, J.M. Weinberg, and M.A. Venkatachalam. 1997. Internucleosomal DNA cleavage triggered by plasma membrane damage during necrotic cell death. Involvement of serine but not cysteine proteases. Am. J. Pathol. 151:1205-1213.

57. Peterson, R.L., M.M. Bozza, and A.J. Dorner. 1996. Interleukin-11 induces intestinal epithelial cell growth arrest through effects on retinoblastoma protein phosphorylation. Am. J. Pathol. 149:895-902.

58. Zhong, L.T., T. Sarafian, D.J. Kane, A.C. Charles, S.P. Mah, R.H. Edwards, and D.E. Bredesen. 1993. bcl-2 inhibits death of central neural cells induced by multiple agents. Proc. Natl. Acad. Sci. USA. 90:4533-4537.

59. Leng, S.X., and J.A. Elias. 1997. Interleukin-11 inhibits macrophage interleukin-12 production. J. Immunol. 159:2161-2168. 